\title{
PALAVRAS RIMADAS, CORPOS EM CENA
}

\author{
Jonatha Vasconcelos Santos ${ }^{1}$
}

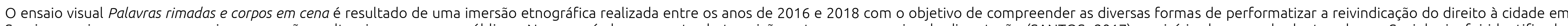

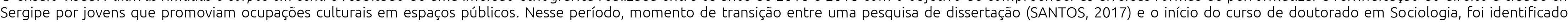

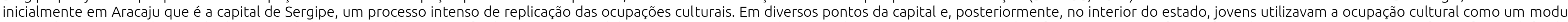

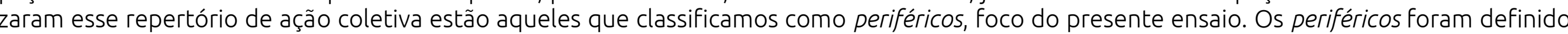

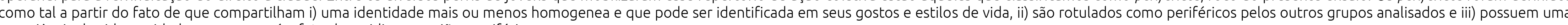
experiência de vida na cidade comum que é o fato de residir em regiões periféricas.

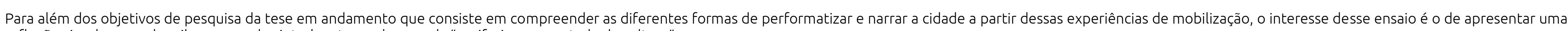
reflexão visual acerca daquilo que um dos interlocutores chamou da "periferia como estado de cultura".

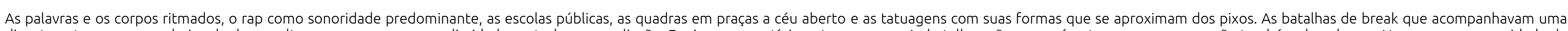

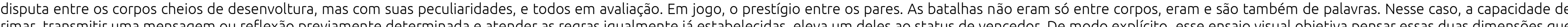

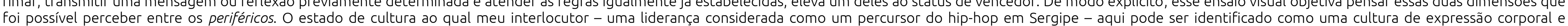
percepção de mundo.

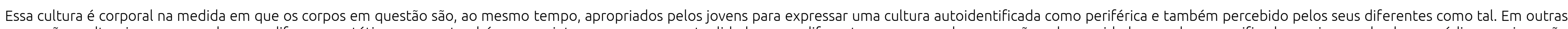

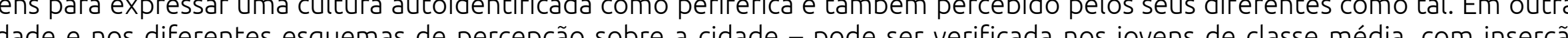

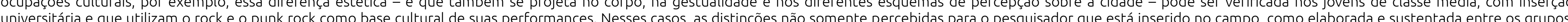
atravessam não somente seus corpos, mas também seus endereços e suas origens sociais. 


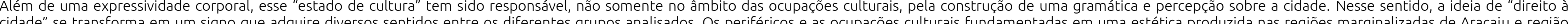

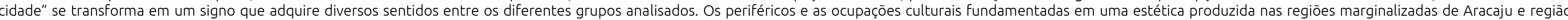
metropolitana trazem, em suas palavras rimadas, algumas dessas pistas sobre qual cidade enunciam e reivindicam. Essa cidade, certamente, não é a mesma dos jovens residentes na zona enobrecida da cidade.

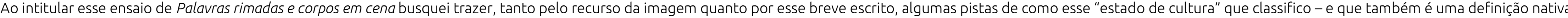

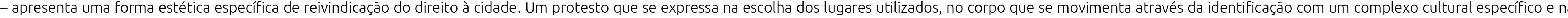
palavra dita. 


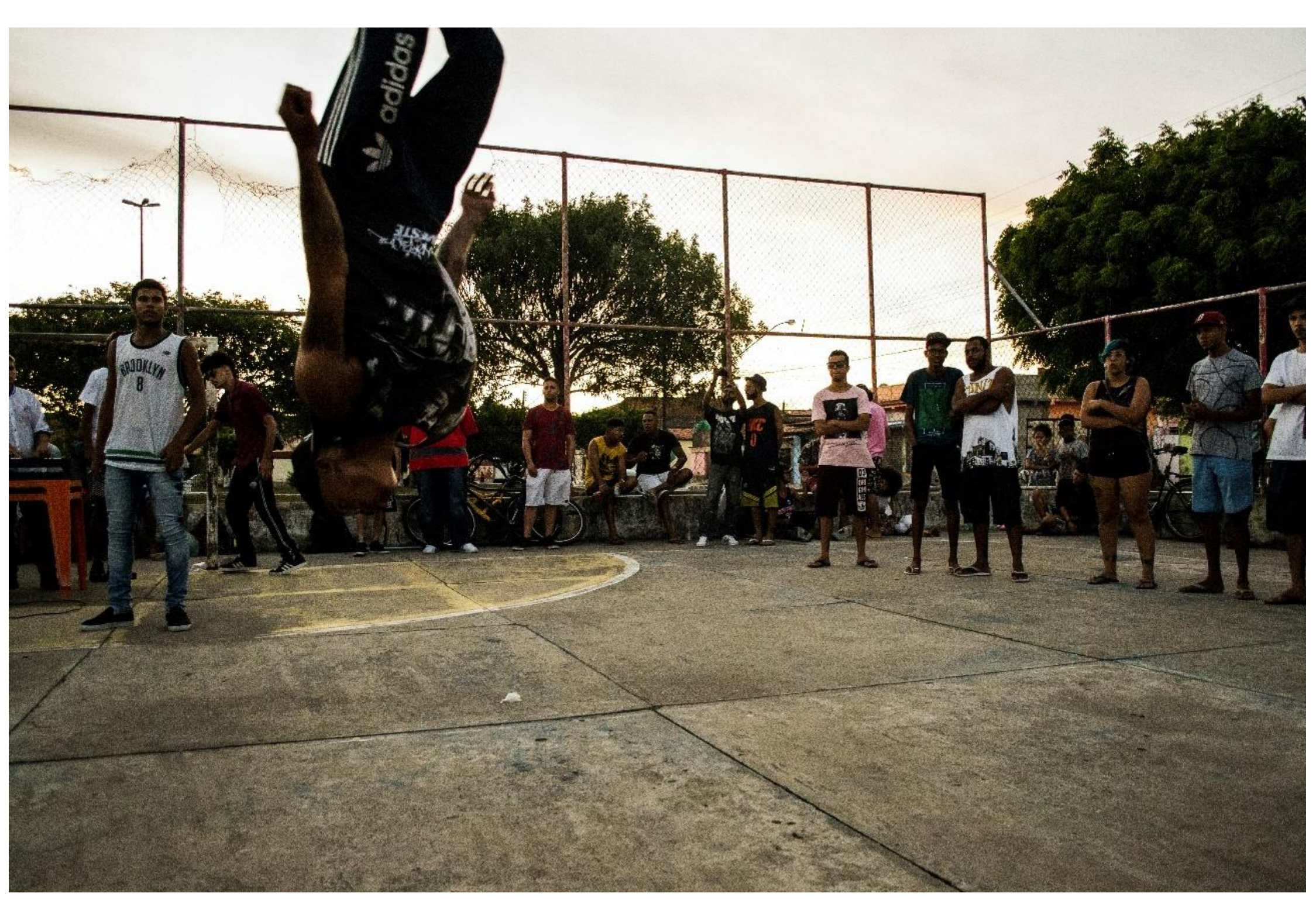






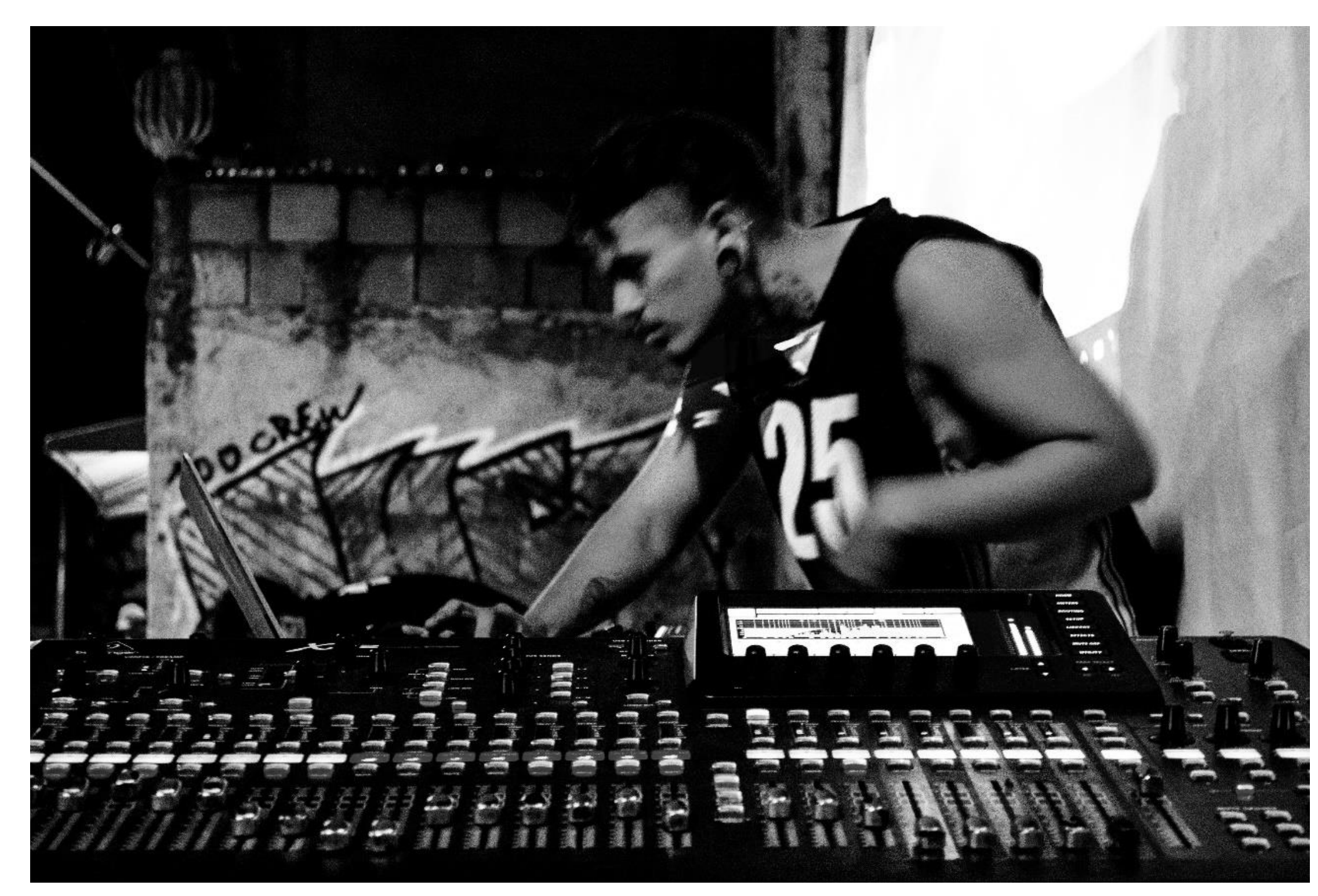




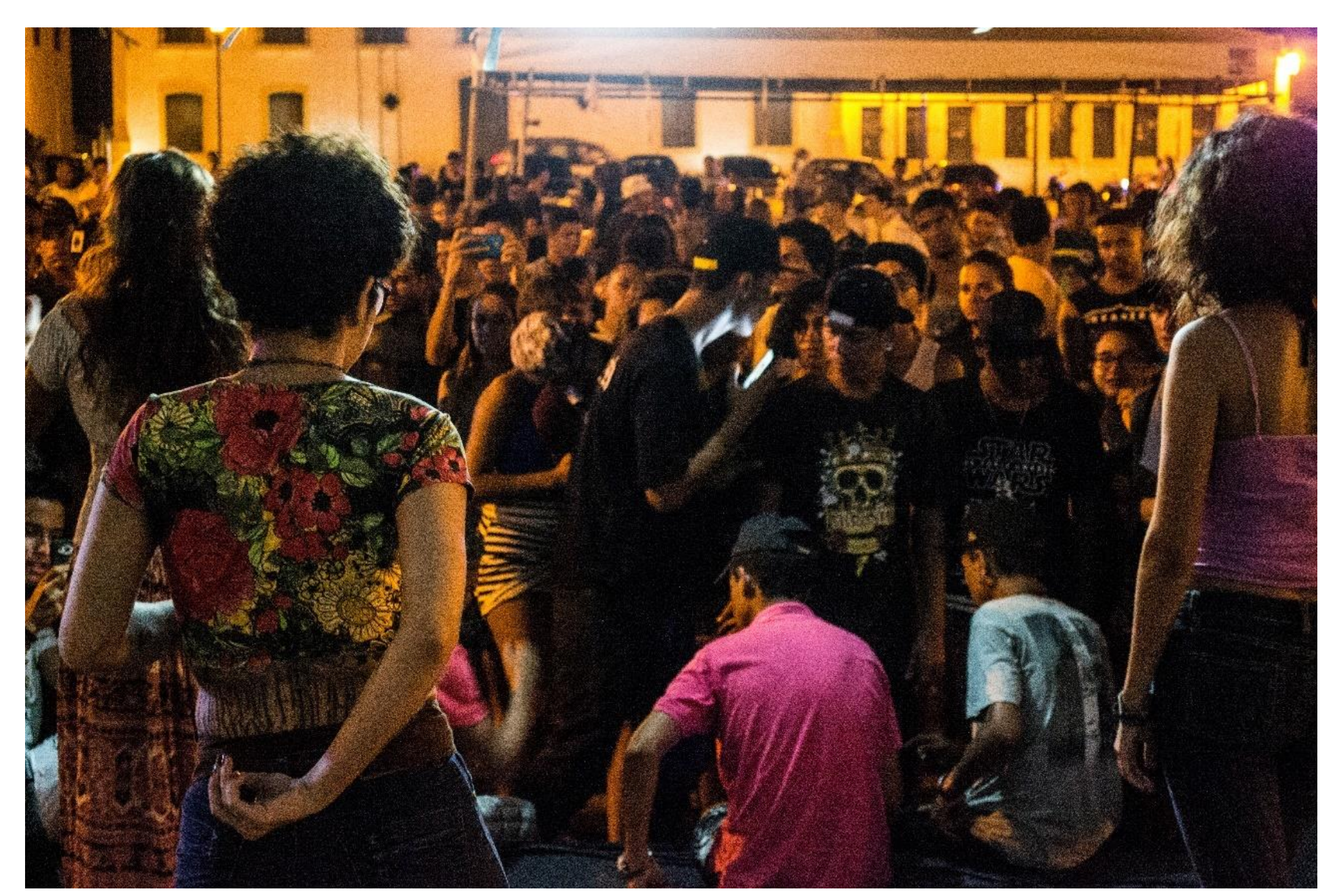




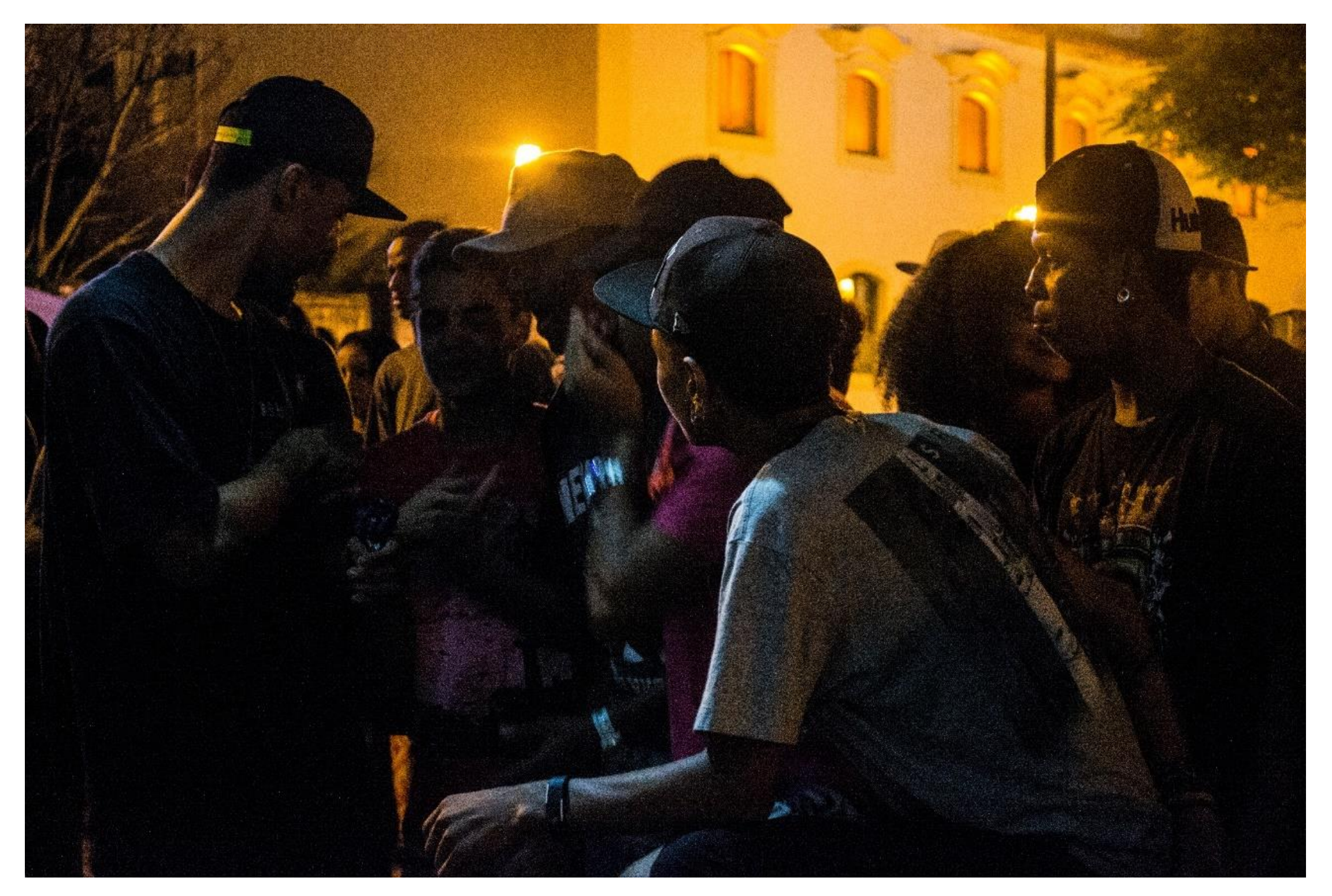




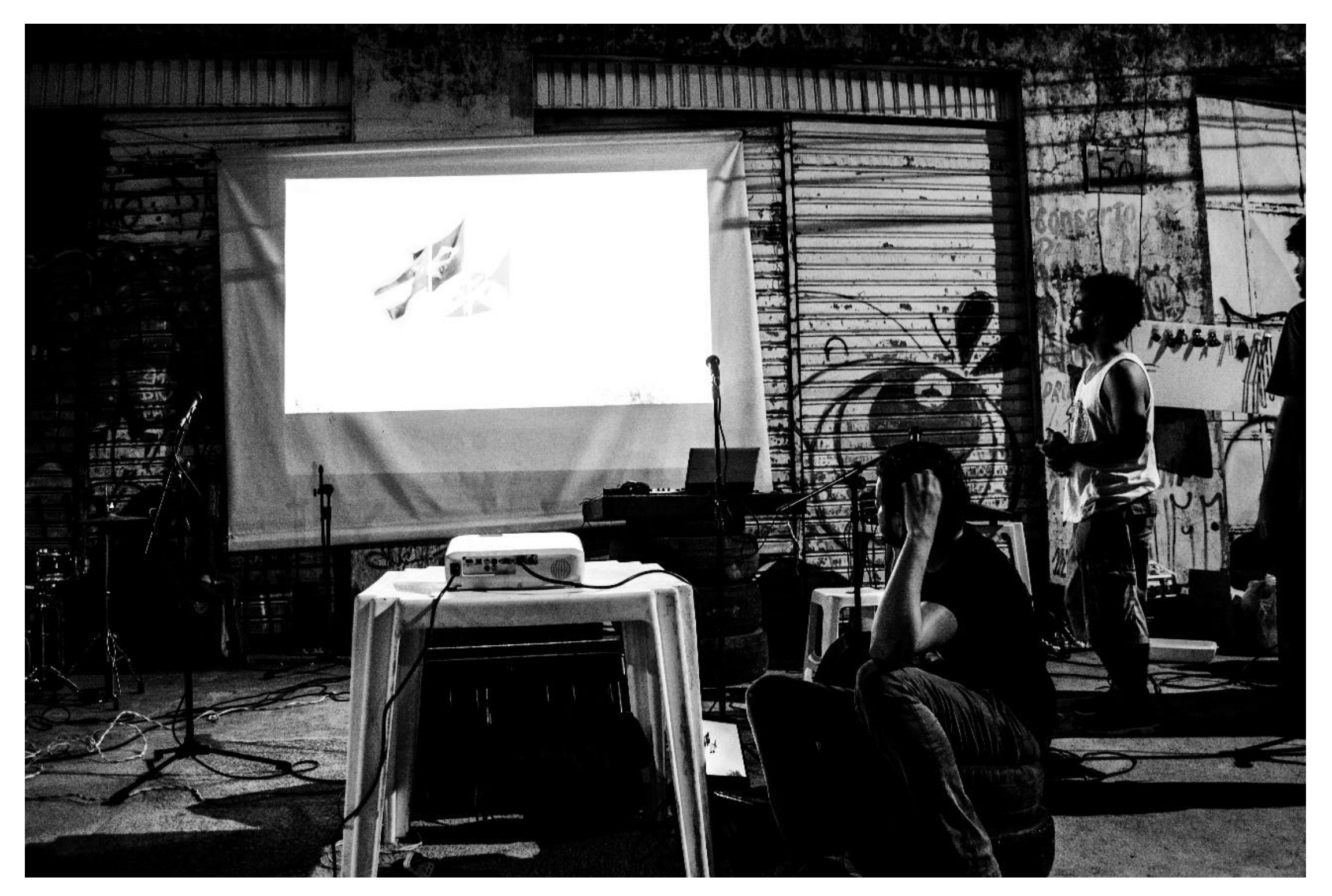




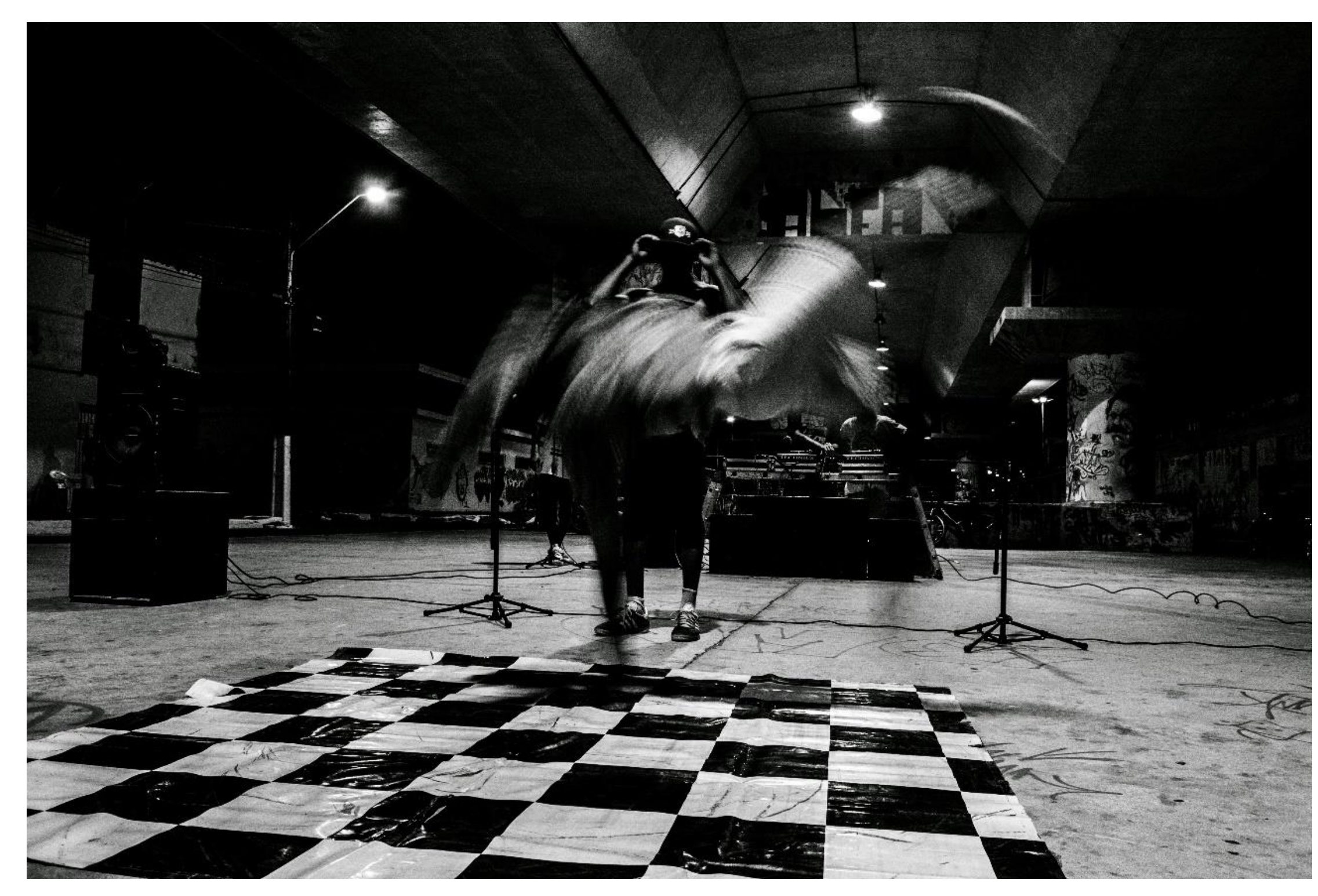




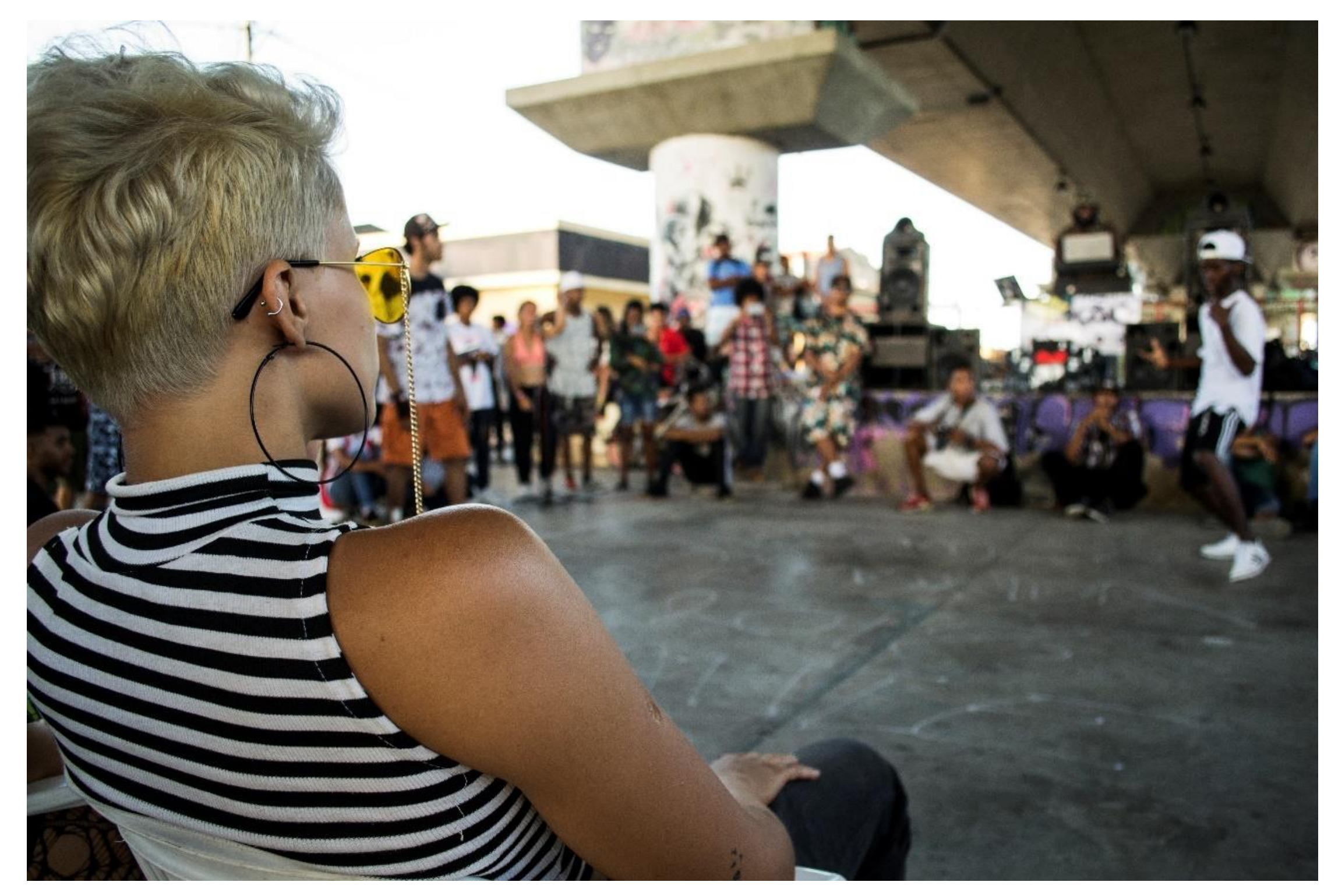




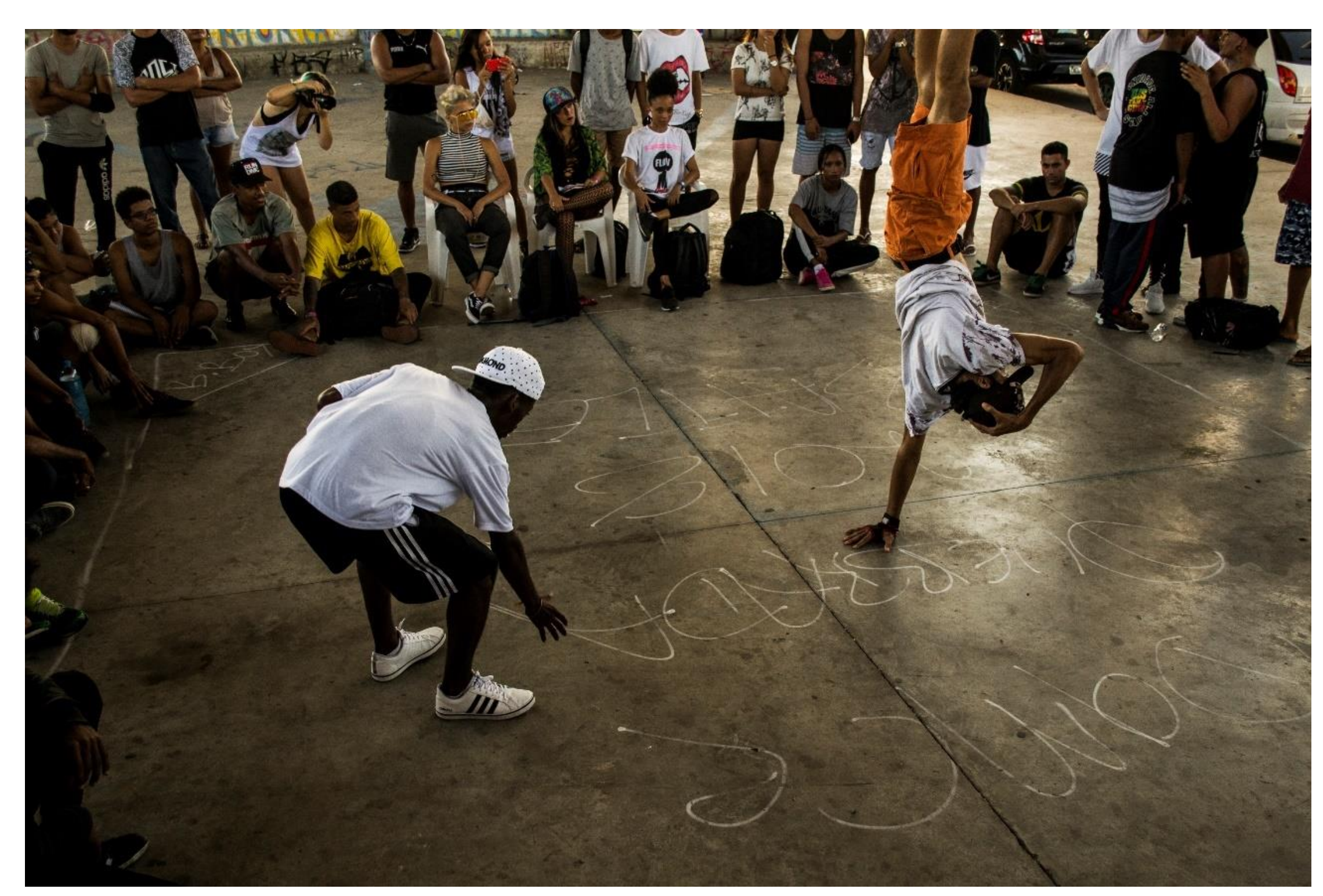




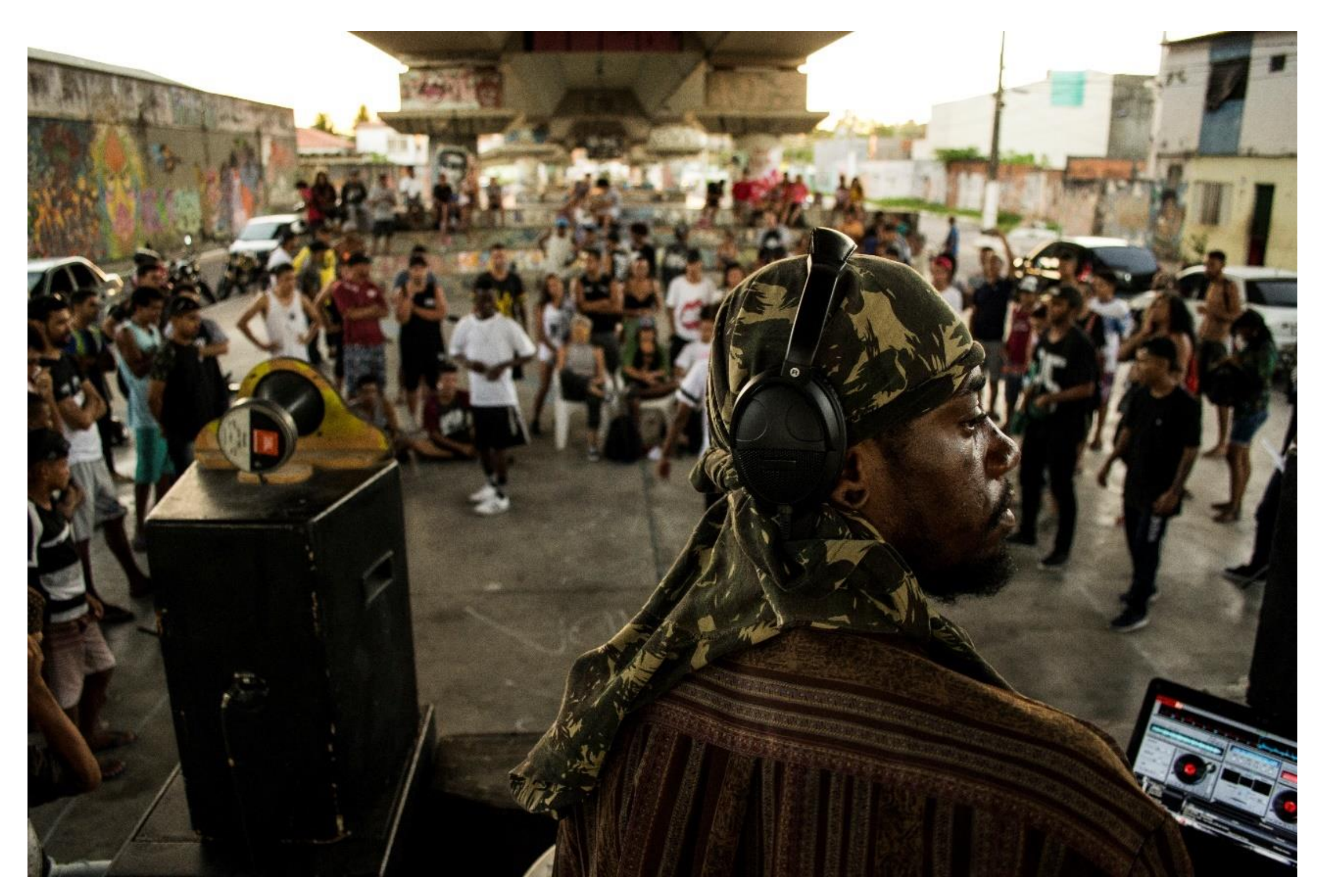




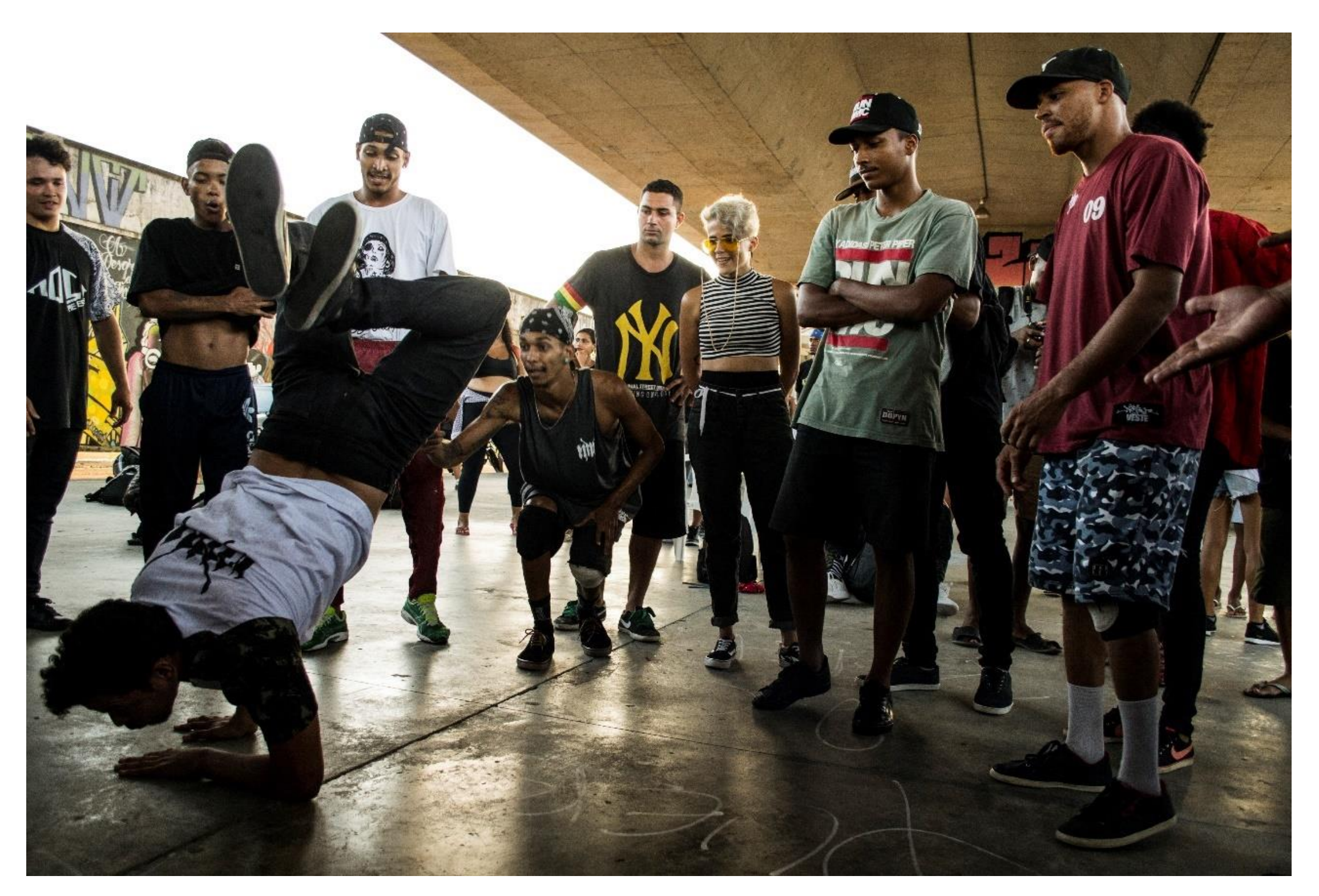


SANTOS, Jonatha Vasconcelos. "As manifestaçōes de junho pra gente não acabou": um estudo sobre as formas de contestação no Coletivo Debaixo em Aracaju. Dissertação (Mestrado em Sociologia). Universidade Federal de Sergipe, 2017.

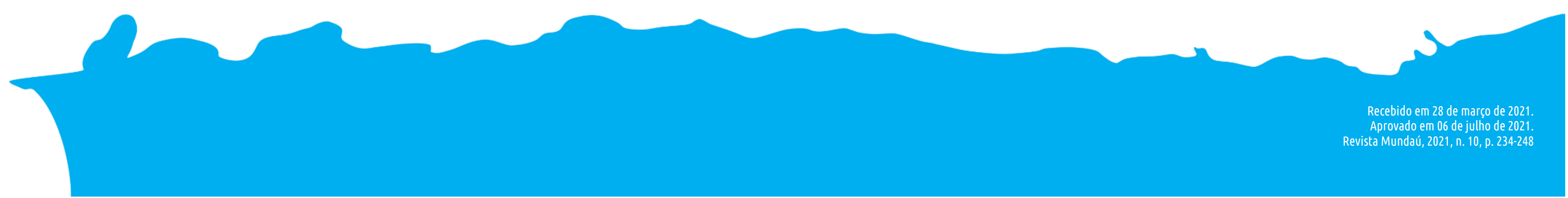

